\title{
Meta-Analisis Efektivitas Penggunaan Model Pembelajaran Tipe TPS dan TSTS Terhadap Kemampuan Memecahkan Masalah Matematika SD
}

\section{Paramita Indah Widyastuti*, Theresia Sri Rahayu²}

12 Universitas Kristen Satya Wacana, Salatiga, Indonesia

*e-mail: 292017144@student.uksw.edu

\begin{abstract}
Abstrak
Penyampaian materi pembelajaran yang kurang menarik sering kali menjadi kendala bagi siswa untuk memahami inti dari materi yang disampaikan. Dibutuhkan keahlian guru dan berbagai model pembelajaran yang menarik untuk dapat membangkitkan semangat siswa dalam memahami materi pembelajaran yang disampaikan dan dapat memecahkan masalahnya sendiri. Penelitian ini bertujuan untuk menganalisis pengaruh efektivitas penggunaan model pembelajaran tipe Think Pair Share dan Two Stay Two Stray terhadap kemampuan memecahkan masalah Matematika Sekolah Dasar dengan menggunakan metode Meta Analisis. Penelitian ini menggunakan pendekatan deskriptif kuantitatif dan metode Meta Analisis dengan menggunakan 20 jurnal sebagai sampelnya10 jurnal yang berkaitan dengan model TPS dan 10 Jurnal yang berkaitan dengan model TSTS. Uji Prasyarat dan uji Ancova untuk mentukan Effect Size. Pada Uji Prasyarat model Think Pair Share dan Two Stay Two Stray telah teruji berdistribusi normal, homogen, dan linear. Effect Size yang dihasilkan adalah sebesar 0,008 $<0,005$ dan nilai pada Partial Eta Square sebesar 0,435 atau 0,2< $0,435 \leq 0,5$ yang artinya bahwa model Think Pair Share dan Two Stay Two Stray memberikan pengaruh yang tergolong sedang terhadap kemampuan memecahkan masalah Matematika tingkat Sekolah Dasar. Model Think Pair Share dan Two Stay Two Stray dapat meningkatkan kemampuan pemecahan masalah Matematika pada siswa sekolah dasar. Implikasi penelitian ini model pembelajaran tersebut dapat diterapkan sehingga dapat meningkatkan suasana belajar yang menyenangkan dan meningkatkan kemampuan pemecahan masalah.
\end{abstract}

Kata kunci: think pair share, two stay two stray, meta analisis

\begin{abstract}
The delivery of learning material that is not interesting is often an obstacle for students to understand the essence of the material presented. It takes teacher expertise and various interesting learning models to be able to arouse students' enthusiasm in understanding the learning material presented and be able to solve their own problems. This study aims to analyze the effect of the effectiveness of using the Think Pair Share and Two Stay Two Stray type of learning model on the ability to solve elementary school mathematics problems using the Meta Analysis method. This study uses a quantitative descriptive approach and Meta-analysis method using 20 journals as a sample, 10 journals related to the TPS model and 10 journals related to the TSTS model. Prerequisite test and Ancova test to determine the Effect Size. In the Prerequisite Test, the Think Pair Share and Two Stay Two Stray models have been tested with normal, homogeneous, and linear distributions. The resulting effect size is $0.008<0.005$ and the value on Partial Eta Square is 0.435 or $0.2<0.435 \leq 0.5$, which means that the Think Pair Share and Two Stay Two Stray models have a moderate effect on the ability to solve mathematics problems at the level of mathematics in Primary school. Think Pair Share and Two Stay Two Stray models can improve math problem solving skills in elementary school students. The implication of this research is that this learning model can be applied so that it can improve a pleasant learning atmosphere and improve problem solving abilities.
\end{abstract}

Keywords: think pair share, two stay two stray, meta-analysis

${ }^{*}$ Corresponding author.

Received 30 Januari 2021; Accepted 1 Maret 2021; Available online 8 April 2021 (C) 2021 MI All Rights Reserved 


\section{Pendahuluan}

Pendidikan adalah proses pembelajaran pengetahuan, keterampilan, serta kemampuan seseorang untuk membentuk sikap dan pola pikir manusia melalui tahapan pengajaran dan pelatihan dengan cara yang baik dan mendidik. Proses pembelajaran dalam satuan pendidikan harus diselenggarakan dengan sebaik-baiknya (Moma, 2017; Nada, Utaminingsih, \& Ardianti, 2018). Seorang guru harus menyusun pembelajaran yang dapat membuat siswa manjadi aktif, merasa senang, mendapatkan tantangan baru, termotivasi untuk belajar lebih giat, membebaskan siswa dalam berkarya sesuai dengan bakat dan minatnya masing-masing (Azmi, 2015; Risvanelli, 2017). Setiap Satuan Pendidikan harus melakukan perencanaan pembelajaran yang dapat meningkatkan efektivitas dan efisiensi dari ketercapaian kompetensi lulusan. Dari pernyataan tersebut, diharapkan setiap peserta didik dapat menguasai seluruh karakteristik tersebut. Untuk membantu peserta didik mencapai pengusaan, pemerintah telah mengupayakan hal tersebut dengan merevisi kurikulum lama dan membuat kurikulum baru yang digunakan saat ini yaitu Kurikulum 2013.

Kurikulum 2013 lebih menekankan kepada kemampuan peserta didik melalui penilaian proses dan output peserta didik. Kurikulum 2013 lebih menekankan student center (berpusat pada peserta didik) (Rahmawati, 2018; Wahyudin, 2018). Namun, masih terdapat guru yang masih menggunakan teacher center (berpusat pada guru) dengan ceramah sebagai cara penyampaian materi. Model pembelajaran konvensional (ceramah) membuat siswa menjadi pasif Ketika mengikuti pembelajaran di kelas (Pramana, Jampel, \& Pudjawan, 2020; Wulandari, Sudatha, \& Simamora, 2020). Hal inilah yang menyebabkan siswa hanya menerima materi pelajaran yang disampaikan oleh guru tanpa menganalisis. Model pembelajaran ceramah juga membuat siswa merasa bosan dalam belajar sehingga membuat siswa kesulitan dalam memahami materi pelajaran (Dadri \& Putra, 2017; Prawitaningrum \& Endarini, 2019). Hal tersebut dapat mempengaruhi hasil belajar belajar siswa. Penelitian yang dilakukan oleh Effendi \& Hendriyani (2020) menyatakan bahwa model pembelajaran konvesional membuat hasil belajar siswa menjadi rendah. Guru seharusnya menjadi fasilitator bagi siswa sehingga siswa lebih mudah memahami materi pembelajaran. Selain itu guru juga harus mengikuti perkembangan jaman dalam mengajar di kelas.

Perkembangan abad ke 21 menjadi perubahan penting bagi setiap mengajar untuk memainkan peranannya sebagai pengajar. Siswa dituntut untuk memiliki keterampilan 4C sesuai dengan kurikulum 2013 yakni meliputi Critical Thinking and Problem Solving, Communication, Collaboration, dan Creativity and Inovation. Yang merupakan keterampilan sebenarnya untuk dituju pada pendidikan abad ke-21 (Lubis, 2018; Yokhebed, 2019). Terdapat berbagai jenis model pembelajaran yang dapat digunakan untuk mendukung proses pemelajaran agar berjalan sesuai dengan yang di rencanakan dan dapat mencapai tujuan pembelajaran. Jenis model pembelajaran diantaranya adalah Kooperatif (CL, Cooperative Learning), Kontekstual (CTL, Contextual Teaching and Learning), Pembelajaran Langsung (DL, Direct Learning), Pembelajaran Berbasis masalah (PBL, Problem Based Learning), Realistik (RME, Realistic Mathematics Education) (Purnamawati, Suardika, \& Manuaba, 2014; Sastrawan, Sedanayasa, \& Suwatra, 2014). Model pembelajaran dari waktu ke waktu selalu mengalami perkembangan. Peneliti di bidang pendidikan berlomba-lomba ingin mengembangkan berbagai jenis model pembelajaran yang dapat digunakan sesuai dengan perkembangan zaman saat ini.

Model pembelajaran yang memiliki banyak perkembangan salah satunya adalah model Kooperatif (CL, Cooperative Learning). Kooperatif (CL, Cooperative Learning) merupakan jenis model pembelajaran dengan cara berkelompok untuk menyelesaikan masalah dan persoalan, mengkonstruksi konsep, dan memahami materi secara mendalam (Sulfemi, 2019; Wati \& Fatimah, 2016). Pembelajaran akan menitikberatkan pada kerjasama kelompok peserta didik tanpa adanya bimbingan dari gurunya, peran guru hanya sebagai fasilitator yang mendampingi peserta didik dalam menyelesaikan pekerjannya, sehingga 
peserta didik akan aktif dalam pembelajaran. Penggunaan model pembelajaran Kooperatif (CL, Cooperative Learning) dapat dikatakan model pembelajaran yang kompleks karena sesuai dengan aspek yang dinilai pada Kurikulum 2013 yaitu aspek sikap, pengetahuan, dan keterampilan, model pembelajaran tersebut dapat mewakili penilaian ketiga aspek untuk peserta didik (Dadri \& Putra, 2017; Dewi, Wiyasa, \& Asri, 2017). Model pembelajaran ini cocok diterapkan pada mata pelajaran Matematika (Lagur, Makur, \& Ramda, 2018; Susanti, 2014). Matematika wajib diberikan kepada seluruh siswa mulai dari jenjang sekolah dasar hingga menengah. Tujuannya adalah agar dibekali kemampuan untuk berpikir kritis, logis, kreatif, analisis, dan dapat bekerjasama untuk pengembangan kemampuan memecahkan masalah dalam Matematika (Saleh, Anwar Bey, \& Kodirun, 2018; Susanti, 2014). Model pembelajaran Kooperatif (CL, Cooperative Learning) dinilai mampu untuk memberikan kesempatan kepada peserta didik untuk mendapatkan pengalaman baru dan kemampuan dalam pemecahan masalah Matematika (Angriani, Bernard, Nur, \& Nurjawahirah, 2016; Prabaningrum \& Putra, 2019). Kooperatif (CL, Cooperative Learning) yang dapat digunakan adalah model Think Pair Share (TPS) dan Two Stay Two Stray (TSTS). Dengan menggunakan model pembelajaran TPS dan TSTS ini, diharapkan peserta didik dapat berdiskusi dan dapat memecahkan masalah dalam Matematika.

Terdapat perbedaan antara TPS dan TSTS. TPS (Think Pair Share) adalah model pembelajaran berpasangan dimana peserta didik diberikan kesempatan untuk memecahkan masalahnya secara individu lalu memasangkannya dengan teman lain dan dapat saling share jawaban yang didapat dan mendapatkan solusi terbaik untuk masalah yang dihadapi, dengan begitu TPS dapat memberikan kesempatan kepada peserta didik untuk bekerja secara individu dan kelompok/berpasangan (Suryaningsih, Putra, \& Negara, 2017; Virgiana \& Wasitohadi, 2016). Sedangkan TSTS (Two Stay Two Stray) adalah model pembelajaran kooperatif dimana kelompok terdiri dari 4 peserta didik, dimana kelompok akan dibagi menjadi 2 kubu yaitu yang pertama 2 peserta didik stay atau tinggal di tempat dan 2 peserta didik lain stray atau berkeliling mencari materi dan memiliki tugasnya masing-masing. Stay bertugas untuk tetap berada dalam kelompok dan tugas stray adalah berkeliling ke kelompok-kelompok lain untuk mendapatkan informasi lainnya. Setelah selesai kelompok stray akan kembali ke kelompok semula dan menshare hasil nya kepada kelompok stay.

Model kooperatif tipe Two Stay Two Stray merupakan tipe pembelajaran kooperatif yang dapat memberikan kesempatan bagi peserta didik untuk saling bekerjasama dalam memperoleh materi atau informasi dari kelompok lain (Dharsana \& Sidabutar, 2018; Mulyantini, Suranata, \& Margunayasa, 2019). Model ini memberi kesempatan kepada setiap kelompok untuk membagikan hasil dan informasi dengan kelompok lainnya. Model pembelajaran Two Stay Two Stray membuat peserta didik dapat belajar untuk memecahkan masalah dengan nggotan kelompoknya, dimana 2 peserta didik dari kelompok tersebut akan bertukar informasi ke kedua anggota keompok lain yang tinggal (Darmayasa, Suara, \& Manuaba, 2013; Sujana, Dharsana, \& Jayanta, 2018). Dari pendapat para ahli diatas, dapat disimpulkan bahwa model TSTS merupakan model pembelajaran secara berkelompok yang beranggotakan 4 orang dimana 2 orang tetap tinggal yang berperan untuk membagikan informasi yang telah didiskusikan oleh kelompoknya dan 2 orang lagi berperan sebagai tamu untuk mencari informasi dari kelompok yang lain. Model pembelajaran ini dapat meningkatkan keaktifan peserta didik selama proses pembelajaran berlangsung karena terjadi interaksi, diskusi, juga saling bertukar pikiran antar kelompok.

Sudah terdapat beberapa penelitian yang meneliti perbandingan antara model TPS (Think Pair Share) dan TSTS (Two Stay Two Stray). Penelitian pertama dilakukan oleh Astesya \& Rahayu (2018) menunjukkan bahwa model TSTS lebih efektif dibandingkan dengan model TPS. Dan penelitian kedua yang dilakukan oleh Ikram (2018) menyatakan model TPS lebih efektif dibandingkan dengan model TSTS. Perbedaan hasil penelitian tersebut membuat keraguan bagi peneliti tentang model pembelajaran mana yang lebih unggul dalam hal pemecahan masalah Matematika SD. Namun, pada penelitian sebelumnya terkait efektivitas penggunaan model pembelajaran TPS dan TSTS terhadap kemampuan 
memecahkan masalah Matematika SD belum terdapat tindak lenjut yang lebih dalam untuk hasil yang diinginkan.

Terlepas dari latar belakarang masalah tersebut, perlunya dilakukan penelitian dengan menggunakan meta analisis pada jurnal-jurnal nasional baik yang sudah terakreditasi Sinta atau tidak. Tujuannya adalah untuk menganalisis pengaruh penggunaan model pembelajaran TPS dan TSTS terhadap kemampuan memecahkan masalah Matematika SD. Berdasarkan uraian tersebut maka dilakukan penelitian dengan judul "Meta Analisis-Efektivitas Penggunaan Model Pembelajaran TPS dan TSTS Terhadap Kemampuan Memecahkan Masalah Matematika".

\section{Metode}

Jenis penelitian yang digunakan adalah oleh peneliti dalam penelitian ini yaitu dengan menggunakan metode kajian Meta Analisis. Cara kerja meta analisis adalah dengan menggabungkan antara dua penelitian atau lebih yang mempunyai kerakteristik yang sejenis sehingga dapat diperoleh kumpulan data secara kuantitatif yang selanjutnya akan dicari Effect Size nya. Penelitian yang akan dilakukan yaitu dengan menggunakan model kooperatif tipe Think Pair Share (TPS) dan Two Stay Two Stray (TSTS). Peneliti mengumpulkan data dengan mencari jurnal.

Pemilihan data pada penelitian ini menggunakan studi meta analisis dengan menantukan inklusi dan eksklusi dalam pemilihan jurnal dan data yang akan digunakan untuk membandingkan model kooperatif tipe Think Pair Share (TPS) dan Two Stay Two Stray (TSTS) terhadap kemampuan memecahkan masalah Matematika SD. Dalam penelitian ini peneliti akan menggabungkan berbagai jenis jurnal dengan kriteria dan topik yang sama yang kemudian diambil data yang relevan sebagai bahan perbandingan kedua model pembelajaran, jurnal yang digunakan adalah jurnal dari peneliti sebelumnya yang telah dipublikasikan baik dalam wilayah nasional maupun internasional.

Tenik pengumpulan data pada penelitian ini adalah dengan mengumpulkan jurnaljurnal online dengan kriteria sebagai berikut : 1). Artikel jurnal yang digunakan adalah artikel yang dibuat oleh peneliti umum atau mahasiswa lain, 2). Artikel jurnal merupakan terbitan 10 tahun terakhir yaitu mulai dari tahun 2011-2021, 3). Artikel jurnal menyangkut tentang model kooperati tipe Think Pair Share (TPS) dan Two Stay Two Stray (TSTS) terhadap kemampuan memecahkan masalah Matematika SD, 4). Jenjang artikel jurnal adalah jenjang Sekolah Dasar, 5). Lingkup penelitian yang digunakan adalah wilayah Indonesia, dan 5). Mengutamakan pencarian jurnal dengan akreditasi Sinta. Dari kriteria tersebut terkumpul jurnal sebanyak 20 jurnal, diantaranya 10 jurnal terkait dengan model Think Pair Share (TPS) dan 10 jurnal yang terkait dengan model Two Stay Two Stray (TSTS). Jurnal dengan jumlah 20 tersebut kemudian dianalisis secara keseluruhan baik secara isi ataupun data yang dibutuhkan untuk menghitung Effect Size.

Pengolahan data pada penelitian ini menggunakan bantuan SPSS 25.00 for windows. Dengan Uji Prasyarat, Uji Ancova, dan Uji Effect Size. Uji Prasyarat terdiri dari tiga uji yaitu Uji Normalitas, Uji Homogenitas, dan Uji Linearitas. Ketiga uji tersebut digunakan untuk mengetahui apakah data berdistribusi normal, homogen, dan linear. Jika data sudah memenuhi Uji Prasyarat maka dapat dilanjutkan dengan Uji Ancova dilakukan untuk dapat mengetahui ada tidaknya perbedaan yang signifikan antara penggunaan model Think Pair Share dan Two Stay Two Stray terhdap kemampuan memecahkan masalah Matematika SD. Dan yang terakhir adalah Uji Effect Size (besaran efek) dapat menunjukkan bahwa perbedaan yang terstandar antara skor penggunaan model pembelajaran Think Pair Share dan Two Stay Two Stray. Effect Size yang digunakan adalah versi Cohen's d, yang dapat diartikan bahwa semakin besar nilai Effect Size maka akan semakin besar pengaruh model pembelajaran TPS dan TSTS terhadap kemampuan memecahkan masalah Matematika SD.. 


\section{Hasil dan Pembahasan}

Model pembelajaran Think Pair Share merupakan model pembelajaran kooperatif yang menuntut keaktifan setiap siswa, model pembelajaran ini digunakan guru untuk mengkondisikan kelas agar suasana belajar dapat berjalan sebagaimana mestinya. Dalam proses belajar mengajar siswa akan berdiskusi dengan kelompoknya atau pasangannya serta diberikan waktu yang lebih banyak untuk berpikir, merespon, dan saling membantu. Sedangkan model pembelajaran Two Stay Two Stray merupakan model pembelajaran kooperatif dengan mengandalkan kemampuan siswa mencari informasi dan memberikan informasi kepada kelompok lain, model pembelajaran ini akan dapat memberikan waktu kepada peserta didik untuk menemukan sendiri materi yang ingin dicarinya, peran guru hanya sebagai fasilitator saja sehingga peserta didik dapat lebih aktif dalam proses belajar mengajar. Model pembelajaran Think Pair Share dan Two Stay Two Stray dapat memberikan permasalahan dalam kegiatan pembelajarannya untuk dapat diselesaikan oleh siswa sendiri, siswa dapat diarahkan untuk lebih aktif dan mampu membantu siswa lain untuk dapat menuangkan ide-idenya sehingga dapat meningkatkan kemampuan memecahkan masalah Matematika. Model pembelajaran Think Pair Share (TPS) dan Two Stay Two Stray (TSTS) terhadap kemampuan memecahkan masalah Matematika siswa SD dinyatakan memiliki pengaruh yang tergolong sedang, hal tersebut dapat dibuktikan dengan rakaian pengujian yang telah dilakukan dengan data yang diperoleh dari 20 jurnal online. Berikut adalah data yang digunakan dalam penelitian ini, data merupakan perolehan ratarata skor pretest dan skor posttest dari 10 jurnal yang berkaitan dengan model Think Pair Share (TPS) dan 10 data berasal dari model dan Two Stay Two Stray (TSTS) ditunjukkan pada tabel 1 berikut.

Tabel 1. Research Gap Model Pembelajaran TPS dan TSTS

\begin{tabular}{|c|c|c|c|c|c|c|c|}
\hline kode & $\begin{array}{l}\text { Pre- } \\
\text { test }\end{array}$ & $\begin{array}{l}\text { Post- } \\
\text { Test }\end{array}$ & Peningkatan & kode & $\begin{array}{l}\text { Pre- } \\
\text { test }\end{array}$ & $\begin{array}{l}\text { Post - } \\
\text { Test }\end{array}$ & Peningkatan \\
\hline TPS01 & 46,40 & 71,84 & 25,44 & TSTS01 & 58,33 & 78,66 & 20,33 \\
\hline TPS02 & 38,33 & 76,79 & 38,46 & TSTS02 & 70,54 & 75,90 & 5,36 \\
\hline TPS03 & 59,92 & 78,81 & 18,89 & TSTS03 & 62,95 & 90,86 & 27,91 \\
\hline TPS04 & 70,30 & 88,30 & 18,00 & TSTS04 & 55,20 & 76,20 & 21,00 \\
\hline TPS05 & 65,5 & 73,75 & 8,25 & TSTS05 & 38,00 & 66,00 & 28,00 \\
\hline TPS06 & 57,4 & 80,4 & 23,00 & TSTS06 & 52,00 & 78,50 & 26,50 \\
\hline TPS07 & 30,00 & 66 & 36,00 & TSTS07 & 54,03 & 80,54 & 26,51 \\
\hline TPS08 & 78,05 & 92,50 & 14,45 & TSTS08 & 33,3 & 83,3 & 50,00 \\
\hline TPS09 & 70 & 85,6 & 15,60 & TSTSO9 & 50,53 & 73,33 & 22,80 \\
\hline TPS10 & 48,39 & 88 & 39,61 & TSTS10 & 50,75 & 68,95 & 18,20 \\
\hline $\begin{array}{l}\text { Rata- } \\
\text { rata }\end{array}$ & 56,43 & 80,20 & 23,77 & $\begin{array}{c}\text { Rata- } \\
\text { rata }\end{array}$ & 52,56 & 77,22 & 24,66 \\
\hline
\end{tabular}

Berdasarkan tabel diatas peningkatan didapatkan melalui selisih antara skor pretest dan posttest sehingga dihasilkan peningkatan yang utuh. Dari komparasi atau perbandingan model Think Pair Share (TPS) dan Two Stay Two Stray (TSTS) yang dilihar dari rata-rata peningkatannya diperoleh hasil model Think Pair Share (TPS) dengan nilai rata-rata sebesar 23,77 sedangkan model pembelajaran Two Stay Two Stray (TSTS) memperoleh hasil ratarata peningkatan sebesar 24,66. Dapat disimpulkan bahwa dari segi komparasi atau perbandingan yang dilihat dari segi peningkatan hasil skor pretest dan posttest maka model Two Stay Two Stray (TSTS) lebih baik dibandingkan dengan model Think Pair Share (TPS). Namun komparasi dari segi peningkatan bukan satu satunya penentu model manakah yang lebih efektif digunakan.

Sesuai dengan data skor pretest dan skor posttest yang diperoleh dari 20 jurnal maka dapat dilaksanakan pengujian terhadap data tersebut diantaranya adalah Uji Prasyarat, Uji 
Ancova, dan Uji Effect Size. Uji Prasyarat melalui 3 pengujian yaitu Uji Normalitas, Uji Homogenitas, dan Uji Linearitas. Uji prasyarat model pembelajaran Think Pair Share dan Two Stay Two Stray memiliki hasil yang normal, homogen, dan linear. Uji Normalitas dengan menggunakan teknik Shapiro-Wilk karena dinilai lebih efektif untuk digunakan dalam jumlah data sebanyak 20 data.

Uji Normalitas kemampuan memecahkan masalah Matematika dari skor pretest dan posttest model pembelajaran Think Pair Share dan Two Stay Two Stray dapat dijabarkan jika nilai signifikasi > 0,05 maka data dapat dikatakan berdistribusi normal, namun jika nilai signifikasi < 0,05 maka data tidak berdistribusi normal. Hasil dari Uji Normalitas pada seluruh data dapat dikatakan normal, dapat dibuktikan dengan nilai signiikasi dari: a). skor pretest model pembelajaran Think Pair Share adalah 0,841 >0,05 yang artinya berdistribusi normal, b). skor posttest model pembelajaran Think Pair Share adalah 0,910>0,05 yang artinya berdistribusi normal, c). skor pretest model pembelajaran Two Stay Two Stray adalah 0,722 $>0,05$ yang artinya berdistribusi normal, dan d). skor posttest model pembelajaran Two Stay Two Stray adalah 0,943 > 0,05 yang artinya berdistribusi normal. Dapat disimpulkan bahwa seluruh data berdistribusi normal karena nilai signifikasi $>0,005$.

Uji Homogenitas digunakan untuk dapat mengetahui apakah sampel data skor artikel jurnal yang telah dikumpulkan dari masing-masing model pembelajaran Think Pair Share dan Two Stay Two Stray berdistribusi homogen (mempunyai variansi yang sama) atau tidak homogen (mempunyai variansi yang berbeda). Data dapat dikatakan homogen jika nilai signifikasi $>0,05$ dan data tidak homogen jika nilai signifikasi $<0,05$. Pada penelitian ini uji homogenitas untuk mengetahui pretest dan posttest dari kedua model pembelajaran apakah homogen atau tidak homogen. Berikut ini adalah hasil Uji Homogenitas dengan skor pretest dan posttest dari kedua model pembelajaran Think Pair Share dan Two Stay Two Stray. Hasil Uji homogenitas menunjukkan bahwa data memiliki hasil hubungan yang homogen, dapat dilihat dari data pretest dari model pembelajaran Think Pair Share dan Two Stay Two Stray menunjukkan nilai signifikasi sebesar 0,169>0,05 sedangkan data posttest dari model pembelajaran Think Pair Share dan Two Stay Two Stray menunjukkan nilai signifikasi sebesar $0,431>0,05$. Sehingga dapat ditarik kesimpulan bahwa penggunaan model pembelajaran Think Pair Share dan Two Stay Two Stray memiliki hubungan yang homogen atau sama.

Uji lineriatas digunakan untuk dapat mengetahui apakah pada variabel bebas dengan menggunakan model pembelajaran Think Pair Share dan Two Stay Two Stray terhadap variabel terikat menggunakan kemampuan memecahkan masalah mempunyai hubungan yang linear atau tidak secara signifikan. Data dapat dikatakan linear jika nilai signifikasi > 0,05 dan tidak linear jika nilai signifikasi $<0,05$. Penelitian ini menguji kedua model pembelajaran untuk diketahui apakah model tersebut linear atau tidak. Dibawah ini adalah tabel hasil pengujian linearitas skor pretest dan posttest pada model pembelajaran Think Pair Share dan Two Stay Two Stray. Hasil Uji linearitas pretest dan posttest menggunakan model pembelajaran Think Pair Share memperolah nilai signifikasi sebesar 0,165 $>0,05$ sehingga dapat disimpulkan bahwa pretest dan posttest menggunakan model pembelajaran Think Pair Share memiliki hubungan yang linear. Uji Linearitas pretest dan posttest menggunakan model pembelajaran Two Stay Two Stray memperoleh nilai signifikasi sebesar 0,277 > 0,05 sehingga dapat disimpulkan bahwa pretest dan posttest menggunakan model pembelajaran Two Stay Two Stray mempunyai hubungan yang linear.

Uji Ancova data bertujuan untuk mengetahui pengaruh perbedaan kedua model pembelajaran TPS dan TSTS. Hasil pengujian Ancova berbantuan SPSS 25.00 for windows, dilaporkan dalam tabel berikut: 
Tabel 2. Hasil Uji Ancova Tests of Between-Subjects Effects

\begin{tabular}{|c|c|c|c|c|c|c|}
\hline \multicolumn{7}{|c|}{ Dependent Variable: Posttest } \\
\hline Source & $\begin{array}{l}\text { Type III Sum } \\
\text { of Squares }\end{array}$ & df & $\begin{array}{l}\text { Mean } \\
\text { Square }\end{array}$ & $\mathbf{F}$ & Sig. & $\begin{array}{c}\text { Partial Eta } \\
\text { Squared }\end{array}$ \\
\hline Corrected Model & $411,061^{a}$ & 2 & 205,531 & 6,533 & ,008 & ,435 \\
\hline Intercept & 4677,443 & 1 & 4677,443 & 148,677 &, 000 & ,897 \\
\hline Pretest & 138,001 & 1 & 138,001 & 4,386 & ,052 & 205 \\
\hline Model & 215,026 & 1 & 215,026 & 6,835 & ,018 & ,287 \\
\hline Error & 534,828 & 17 & 31,460 & & & \\
\hline Total & 123861,410 & 20 & & & & \\
\hline Corrected Total & 945,889 & 19 & & & & \\
\hline
\end{tabular}

a. $R$ Squared $=, 435$ (Adjusted R Squared $=, 368$ )

Berdasarkan uji Ancova yang telah dilakukan dengan menggunakan Univariate, menunjukkan nilai Sig. sebesar 0,018 yang berarti lebih kecil dari 0,05 $(0,018<0,05)$. Berdasarkan Uji Ancova membuktikan bahwa f hitung $>\mathrm{f}$ tabel yakni 6,835 > 3,20 dan nilai signifikasinya adalah 0,008 $<0,05$ yang membuktikan bahwa $\mathrm{H}_{\mathrm{o}}$ ditolak dan $\mathrm{H}_{\mathrm{a}}$ diterima. Sehingga disimpulkan terdapat pengaruh dalam penggunaan mdel TPS dan TSTS ditinjau dari peningkatan kemampuan memecahkan masalah Matematika SD. Sesuai dengan hasil pengujian Ancova pada kolom Model di atas dapat ditarik kesimpulan bahwa sig. Sebesar 0,018 . $F$ hitung yang diperoleh adalah sebesar 6,835 dan $F$ tabel dari perolehan data diatas adalah 3,20. $\mathrm{F}$ tabel dicari menggunakan bantuan tabel $\mathrm{F}$ dengan rumus df $1=\mathrm{K}-1$ dan df2 $=\mathrm{N}-\mathrm{K}$.

Uji Effect Size dapat dilakukan bersamaan dengan Uji Ancova. Setelah diketahui hasil Uji Hipotesis yang membuktikan bahwa ada perbedaan yang cukup signifikan dalam penggunaan model TPS dan TSTS. Selanjutnya pada perhitungan Effect Size dari kedua mdel menggunakan pengujian Ancova yang diketahui Partial Eta Square sebesar 0,435 dengan nilai signifikasi sebesar 0,008. Hal tersebut menunjukkan mdel TPS dan TSTS dapat memberikan pengaruh yang tergolong sedang terhadap kemampuan memecahkan masalah Matematika. Maka sesuai dengan interpretasi Effect Size versi Cohen's d pada tabel 01 maka Effect Size dapat dilihat dari besaran Partial Eta Square dimana 0,2 < 0,435<0,5 yang artinya bahwa pengaruh model pembelajaran TPS dan TSTS terhadap kemampuan memecahkan masalah Matematika SD memiliki pengaruh yang tergolong sedang. Hal tersebut disebabkan oleh beberapa hal yaitu sebagai berikut.

Pertama, model pembelajaran Think Pair Share merupakan model pembelajaran kooperatif yang menuntut keaktifan setiap siswa, model pembelajaran ini digunakan guru untuk mengkondisikan kelas agar suasana belajar dapat berjalan sebagaimana mestinya (Anggreni, Asri, \& Ganing, 2017; Dewi, Ganing, \& Suadnyana, 2017). Dalam proses belajar mengajar siswa akan berdiskusi dengan kelompoknya atau pasangannya serta diberikan waktu yang lebih banyak untuk berpikir, merespon, dan saling membantu. Pengertian Think Pair Share (TPS) atau berpikir berpasangan berbagi merupakan jenis pembelajaran kooperatif yang di reancang untuk mempengaruhi pola interaksi siswa. TPS mendorong partisipasi siswa untuk lebih aktif karena peserta didik akan melalui fase bekerja sendiri dan juga bekerjasama dengan siswa lain (Suantara, Ganing, Agung, \& Wulandari, 2019; Wulandari, Abadi, \& Suniasih, 2018). Setiap kelompok akan beranggotakan siswa dan guru akan memerikan tugas. Setiap individu siswa akan berpasangan yang selanjutnya aka mendiskusikan hasil dari pekerjaan nya masing-masing. Dengan berpasangan maka jawaban akan saling dibagikan dan didiskusikan untuk memperbaiki tugas individu. Pasangan siswa akan membagikan hasil diskusi di depan kelas. Model ini merupakan pembelajaran yang menggunakan strategi kinerja dalam kelompok dimana peserta didik 
secara individual mengerjakan tugas yang diberikan guru lalu dipasangkan kemudian dilakuan berkelompok dengan memasangkan jawaban dan dapat berbagi informasi (Fitriani \& Wuryandari, 2019; Tela, Yulian, \& Budianingsih, 2019). Tujuan dari pembelajaran TPS ini adalah untuk melatih setiap peserta didik agar berani. Berdasarkan pendapat para ahli diatas, dapat disimpulkan bahwa model pembelajaran TPS merupakan model pembelajaran dengan menggunakan strategi kerja kelompok dimana peserta didik diberikan kesempatan yang lebih banyak untuk berdiskusi secara berpasangan dengan kata lain berpikir dan berpendapat secara individu untuk menanggapi pendapat orang lain dan saling membantu juga membagi pengetahuan antar peserta didik.

Kedua, Model pembelajaran Two Stay Two Stray ini secara berkelompok yang beranggotakan 4 orang dimana 2 orang tetap tinggal yang berperan untuk membagikan informasi yang telah didiskusikan oleh kelompoknya dan 2 orang lagi berperan sebagai tamu untuk mencari informasi dari kelompok yang lain. Model ini mengandalkan kemampuan siswa mencari informasi dan memberikan informasi kepada kelompok lain, model pembelajaran ini akan dapat memberikan waktu kepada peserta didik untuk menemukan sendiri materi yang ingin dicarinya, peran guru hanya sebagai fasilitator saja sehingga peserta didik dapat lebih aktif dalam proses belajar mengajar (Dharsana \& Sidabutar, 2018; Mulyantini et al., 2019). Model pembelajaran ini dapat meningkatkan keaktifan peserta didik selama proses pembelajaran berlangsung karena terjadi interaksi, diskusi, juga saling bertukar pikiran antar kelompok. Model pembelajaran Think Pair Share dan Two Stay Two Stray dapat memberikan permasalahan dalam kegiatan pembelajarannya untuk dapat diselesaikan oleh siswa sendiri, siswa dapat diarahkan untuk lebih aktif dan mampu membantu siswa lain untuk dapat menuangkan ide-idenya sehingga dapat meningkatkan kemampuan memecahkan masalah Matematika.

Penelitian yang dilakukan oleh Prasetiyo, Yusmin, \& Hartoyo (2014) menyatakan bahwa tipe cooperative learning yang menghasilkan pengaruh paling besar dan konsisten adalah tipe Think Pair Share (TPS) dengan Effect Size sebesar 0,898 dan mencapai kontribusi sebesar $31,33 \%$. Penelitian lain dilakukan oleh Nugroho, Dwijayanti, \& Atmoko (2020) diperoleh kemampuan pemecahan masalah matematis siswa menggunakan model pembelajaran yang berbasis lingkungan lebih baik dengan rata-rata Effect Size sebesar 1,245 sedangkan yang menggunakan model pembelajaran berbasis penemuan menunjukkan rata-rata Effect Size sebesar 0,762. Penelitian yang dilakukan oleh Mulyantini et al., (2019) menyatakan bahwa model pembelajaran Two Stay Two Stray dapat meningkatkan minat belajar pada siswa sehingga berpengaruh pada hasil belajar siswa yang meningkat. Implikasi penelitian ini dapat meningkatkan suasana belajar yang menyenangkan sehingga berpengaruh pada kemampuan pemecahan masalah matematis siswa.

\section{Simpulan}

Model pembelajaran Think Pair Share (TPS) dan Two Stay Two Stray (TSTS) terhadap kemampuan memecahkan masalah Matematika siswa SD dinyatakan memiliki pengaruh yang tergolong sedang. Kedua model memiliki pengaruh yang sedang namun jika dikomparasikan penggunaan model TPS lebih berhasil dari segi efisien dan efektif untuk digunakan dalam pembelajaran Matematika jika dibandingkan dengan model TSTS untuk meningkatkan kemampuan memecahkan masalah Matematika SD.

\section{Daftar Pustaka}

Anggreni, P. F., Asri, I. A. S., \& Ganing, N. N. (2017). Pengaruh Model Pembelajaran Kooperatif Tipe Think- Pair-Share ( Tps ) Berbantuan Media Kartu Bergambar Terhadap Penguasaan Kompetensi Pengetahuan Ips Siswa Kelas V Gugus Letkol Wisnu. Mimbar PGSD, https://doi.org/http://dx.doi.org/10.23887/jjpgsd.v5i2.10645

Angriani, A. D., Bernard, B., Nur, R., \& Nurjawahirah, N. (2016). Meningkatkan Kemampuan 
Pemecahan Masalah Melalui Pembelajaran Kooperatif Think-Talk-Write Pada Peserta Didik Kelas Viii1 Mtsn Model Makassar. MaPan: Jurnal Matematika Dan Pembelajaran, 4(1), 11-28. https://doi.org/10.24252/mapan.2016v4n1a2

Astesya, M., \& Rahayu, W. T. S. (2018). Efektivitas Penggunaan Model Pembelajaran Kooperatif Tipe Tsts(Two Stay Two Stray) Dengan Tps (Think Pair Share)Terhadap Hasil Belajar Matematika Siswa Kelas V SD. Didaktika Dwija Indria, 6(2). Retrieved from https://jurnal.fkip.uns.ac.id/index.php/pgsdsolo/article/view/11867

Azmi, N. (2015). Model Pembelajaran Inside Outside Circle (loc)) Untuk Meningkatkan Hasil Belajar Siswa Dalam Proses Pembelajaran. Al Ibtida: Jurnal Pendidikan Guru MI, 2(1), 1-19. https://doi.org/10.24235/al.ibtida.snj.v2i1.180

Dadri, P. C. W., \& Putra, D. (2017). Pengaruh Model Pembelajaran Kooperatif Tipe Numbered Head Together (NHT) Terhadap Hasil Belajar Matematika Kelas IV. International Journal of Elementary Education, 5(2), 1-10. https://doi.org/http://dx.doi.org/10.23887/ijee.v3i2.18517

Darmayasa, I. W. G. S., Suara, I. M., \& Manuaba, I. B. S. (2013). Penerapan Model Pembelajaran Kooperatif Tipe Two Stay Two Strayberbantuan Media Gambar Untuk Meningkatkan Motivasi Dan Hasil Belajar PKn. MIMBAR PGSD Undiksha, 1(1). https://doi.org/http://dx.doi.org/10.23887/jjpgsd.v1i1.922

Dewi, Ganing, \& Suadnyana. (2017). Pengaruh Model Pembelajaran Kooperatif Tipe Think Pair Share Berbantuan Mind Mapping Terhadap Kompetensi Pengetahuan IPA Siswa Kelas V SD Gugus Kompyang Sujana Denpasar Utara. Mlimbar PGSD Undiksha, 5. https://doi.org/http://dx.doi.org/10.23887/jjpgsd.v5i2.10623

Dewi, N. P. D. A., Wiyasa, I. K. N., \& Asri, I. G. A. A. S. (2017). Pengaruh Model Kooperatif Talking Stick Berbantu Question Card terhadap Kompetensi Pengetahuan IPS Siswa kelas IV. Mimbar https://doi.org/http://dx.doi.org/10.23887/jjpgsd.v5i2.10790

Dharsana, G. S., \& Sidabutar. (2018). Pengaruh Model Pembelajaran Kooperatif Tipe Two Stay Two Stray melalui Lesson Study terhadap Hasil Belajar IPA. MIMBAR PGSD Undiksha, 6(2). https://doi.org/http://dx.doi.org/10.23887/jjpgsd.v6i2.19463

Effendi, H., \& Hendriyani, Y. (2020). The Conceptual and Hypothetical Model of Interactive Blended Problem Based Learning. JPI (Jurnal Pendidikan Indonesia), 8(2), 285. https://doi.org/10.23887/jpi-undiksha.v8i2.24162

Fitriani, K., \& Wuryandari, W. (2019). Media Kajian Kewarganegaraan Pengaruh model kooperatif tipe Think Pair Share terhadap kerja sama siswa. Jurnal Civics, 16(1), 8088. https://doi.org/https://doi.org/10.21831/jc.v16i1.21520

Ikram. (2018). Perbandingan Hasil Belajar IPA Peserta Didik Yang Menggunakan Model Pembelajaran Kooperatif Tipe Two Stay Two Stray (TSTS) Dengan Tipe Think Pair Share (TPS) Kelas VIII Mts Negeri Gowa. UIN Alauddin Makassar.

Lagur, D. S., Makur, A. P., \& Ramda, A. H. (2018). Pengaruh Model Pembelajaran Kooperatif Tipe Numbered Head Together (NHT) terhadap Kemampuan Komunikasi Matematis. Mosharafa: Jurnal Pendidikan Matematika, 7(3), 357-368. https://doi.org/https://doi.org/10.31980/mosharafa.v7i3.160

Lubis, A. H. (2018). Integrasi TIK Dalam Pengajaran Bahasa Inggris Di Indonesia Abad Ke21: Mitos Dan Realita. Cakrawala Pendidikan, 37(1), 11-21. Retrieved from https://journal.uny.ac.id/index.php/cp/article/view/16738/pdf.

Moma. (2017). Pengembangan Kemampuan Berpikir Kreatif dan Pemecahan Masalah Matematis Mahasiswa Melalui Metode Diskusi. Cakrawala Pendidikan, 36(1), 130 139. Retrieved from https://journal.uny.ac.id/index.php/cp/article/view/10402/pdf 
Mulyantini, N. L. D., Suranata, K., \& Margunayasa, I. G. (2019). Pengaruh Model Pembelajaran Two Stay Two Stray Terhadap Minat Belajar Ipa Siswa Kelas IV SD. MIMBAR PGSD Undiksha, https://doi.org/http://dx.doi.org/10.23887/jjpgsd.v7i1.17023

Nada, I., Utaminingsih, S., \& Ardianti, S. D. (2018). Penerapan Model Open Ended Problems Berbantuan Cd Pembelajaran Untuk Meningkatkan Kemampuan Berpikir Kreatif Siswa Kelas Iv Sd 1 Golantepus. Jurnal Pendidikan Sekolah Dasar, 4(2), 216. https://doi.org/10.30870/jpsd.v4i2.3856

Nugroho, A. A., Dwijayanti, I., \& Atmoko, P. Y. (2020). Pengaruh Model Pembelajaran Berbasis Penemuan Dan Lingkungan Terhadap Kemampuan Pemecahan Masalah Matematika Melalui Meta Analisis. Aksioma, 9(1). https://doi.org/http://dx.doi.org/10.24127/ajpm.v9i1.2659

Prabaningrum, I. G. A. I., \& Putra, I. K. A. (2019). Pengaruh Model Pembelajaran Kooperatif Team Assisted Individualization Berbantuan Media Semi Konkret Terhadap Kompetensi Pengetahuan Matematika. Jurnal IImiah Sekolah Dasar, 3(4), 414. https://doi.org/10.23887/jisd.v3i4.21775

Pramana, Jampel, \& Pudjawan. (2020). Meningkatkan Hasil Belajar Biologi Melalui E-Modul Berbasis Problem Based Learning. Jurnal Edutech Undiksha, 8(2), 18-32. https://doi.org/http://dx.doi.org/10.23887/jeu.v8i2.28921

Prasetiyo, andi yoga, Yusmin, E., \& Hartoyo, A. (2014). Meta-Analisis Pengaruh Cooperative Learning Terhadap Peningkatan Hasil Belajar Matematika Siswa. Jurnal Pendidikan Dan Pembelajaran Khatulistiwa, 3(2). Retrieved from https://jurnal.untan.ac.id/index.php/jpdpb/article/view/4605

Prawitaningrum, A., \& Endarini, E. (2019). Efektivitas Model CIRC dan GGE Terhadap Kemampuan Berpikir Kreatif Matematika. International Journal of Elementary Education Universitas Pendidikan Ganesha, 3(3), 308-315. https://doi.org/http://dx.doi.org/10.23887/ijee.v3i3.19416

Purnamawati, Suardika, \& Manuaba. (2014). Pengaruh Penerapan Model Pembelajaran Kontekstual Berbasis Lingkungan terhadap Hasil Belajar IPA Siswa Kelas V SD di Gugus I Gusti Ngurah Rai Denpasar Selatan. Mimbar PGSD Undiksha, 2(1). https://doi.org/http://dx.doi.org/10.23887/jjpgsd.v2i1.3195

Rahmawati, A. (2018). Identifikasi Masalah yang Dihadapi Guru dalam Penerapan Kurikulum 2013. Indonesian Journal of Primary Education, 2(1), 114-123. https://doi.org/https://doi.org/10.17509/ijpe.v2i1.14227

Risvanelli. (2017). Peningkatan Hasil Belajar dan Aktivitas Siswa Kelas V Menggunakan Pendekatan Value Clarification Technique (VCT) Pada Pembelajaran PKn di SDN 24 Batang Anai Kabupaten Padang Pariaman. JPPI (Jurnal Penelitian Pendidikan Indonesia), 3(2), 44-56. https://doi.org/10.29210/02017116

Saleh, F., Anwar Bey, \& Kodirun, K. (2018). Hubungan Tingkat Kecemasan Siswa dalam Menghadapi Ujian Akhir Semester dengan Hasil Belajar Matematika Siswa SMA Negeri 2 Kendari. Pendidikan Matematika, 6(1), 29-42. https://doi.org/10.36709/jppm.v6i1.7392

Sastrawan, W., Sedanayasa, \& Suwatra, I. I. W. (2014). Pengaruh Model Pembelajaran Kooperatif Tipe Numbered head Together (NHT) dengan Bantuan Media Software Pembelajaran Terhadap Hasil Belajar IPA Siswa Kelas V SD Gugus III Desa Bengkel Kecamatan Busung Biu. MIMBAR PGSD Undiksha, 2(1), 1-12. https://doi.org/http://dx.doi.org/10.23887/jjpgsd.v2i1.2308

Suantara, I. K. T., Ganing, N. N., Agung, I. G., \& Wulandari, A. (2019). Pengaruh Model Pembelajaran Think Pair Share Berbantuan Media TTS terhadap Kompetensi 
Pengetahuan IPA. Jurnal IImiah Sekolah Dasar, 3(4), 473-480. https://doi.org/http://dx.doi.org/10.23887/jisd.v3i4.21783

Sujana, D. M. A., Dharsana, I. K., \& Jayanta, I. N. L. (2018). Pengaruh Model Pembelajaran Kooperatif Tipe Two Stay Two Stray melalui Lesson Study terhadap Hasil Belajar IPA. MIMBAR PGSD Undiksha, 6(2). https://doi.org/http://dx.doi.org/10.23887/jjpgsd.v6i2.19462

Sulfemi, W. B. (2019). Model Pembelajaran Kooperatif Mind Mapping Berbantu Audio Visual Dalam Meningkatkan Minat, Motivasi Dan Hasil Belajar Ips. Jurnal PIPSI (Jurnal Pendidikan IPS Indonesia), 4(1), 13. https://doi.org/10.26737/jpipsi.v4i1.1204

Suryaningsih, N. K. E., Putra, D. K. N. S., \& Negara, I. G. A. O. (2017). Pengaruh Model Pembelajaran Kooperatif Tipe Think Pair Share (Tps) Terhadap Penguasaan Kompetensi Pengetahuan Ipa Siswa Kelas Iv Sd Gugus Untung Surapati Denpasar Tahun Ajaran 2016/2017. MIMBAR PGSD Undiksha, 5(2). https://doi.org/10.23887/jjpgsd.v5i2.10784

Susanti, V. D. (2014). Efektivitas Model Pembelajaran Portofolio Dan Model Pembelajaran Kooperatif Think Pair and Share (Tps) Terhadap Prestasi Belajar Matematika Ditinjau Dari Kreativitas Siswa Vii Smp Negeri 2 Kebonsari Tahun Ajaran 2011/2012. JIPM $\begin{array}{llll}\text { (Jurnal Ilmiah } & 32 .\end{array}$ https://doi.org/10.25273/jipm.v2i2.476

Tela, Yulian, V. N., \& Budianingsih, Y. (2019). Pengaruh Model Pembelajaran Kooperatif Tipe Think Pair Share (TPS) Terhadap Peningkatan Kemampuan Pemecahan Masalah Matematis Siswa. Biormatika: Jurnal IImiah Fakultas Keguruan Dan IImu Pendidikan, $5(01)$, 114-123. https://doi.org/https://doi.org/10.35569/biormatika.v5i01.464

Virgiana, A., \& Wasitohadi. (2016). Efektivitas Model Problem Based Learning Berbantuan Media Audio Visual Ditinjau Dari Hasil Belajar IPA Siswa Kelas 5 SDN 1 Gadu Sambong - Blora Semester 2 Tahun 2014/2015. Scholaria: Jurnal Pendidikan Dan Kebudayaan, 6(2), 100-118. https://doi.org/10.24246/j.scholaria.2016.v6.i2.p100-118

Wahyudin, W. (2018). Optimalisasi Peran Kepala Sekolah dalam Implementasi Kurikulum 2013. Jurnal Kependidikan, 6(2), 249-265. https://doi.org/10.24090/jk.v6i2.1932

Wati, W., \& Fatimah, R. (2016). Effect Size Model Pembelajaran Kooperatif Tipe Numbered Heads Together (NHT) terhadap Kemampuan Berpikir Kritis Siswa pada Pembelajaran Fisika. Jurnal Ilmiah Pendidikan Fisika Al-Biruni, 5(2), 213-222. https://doi.org/https://doi.org/10.24042/jpifalbiruni.v5i2.121

Wulandari, P., Abadi, I. B. G., \& Suniasih, N. W. (2018). Pengaruh Model Pembelajaran Think Pair Share Berbasis Penilaian Portofolio Terhadap Kompetensi Pengetahuan IPA Siswa Kelas IV SS Negeri Gugus Kapten Kompyang Sujana Denpasar Barat Tahun 2017/2018. MIMBAR PGSD Undiksha, 6(3), 161-168. https://doi.org/10.23887/jjpgsd.v6i3.15772

Wulandari, Sudatha, \& Simamora. (2020). Pengembangan Pembelajaran Blended Pada Mata Kuliah Ahara Yoga Semester II di IHDN Denpasar. Jurnal Edutech Undiksha, 8(1), 1-15. https://doi.org/http://dx.doi.org/10.23887/jeu.v8i1.26459

Yokhebed. (2019). Profil Kompetensi Abad 21: Komunikasi, Kreativitas, Kolaborasi, Berpikir Kritis Pada Calon Guru Biologi Profile of 21st Century Competency: Communication, Creativity, Collaboration, Critical Thinking at Prospective Biology Teachers. BioPedagogi: Jurnal Pembelajaran Biologi, 8(2). Retrieved from https://jurnal.uns.ac.id/pdg/article/view/36154 